\title{
REAKTUALISASI PENGUKURAN ARAH KIBLAT DENGAN METODE SEGITIGA BOLA PADA MASJID DAN MUSHOLLA
}

\author{
Andi Susanto ${ }^{1}$, Diana Nurfadilah ${ }^{2}$, Siti Zaenab ${ }^{3}$ \\ Sekolah Tinggi Ilmu Syariah Darul Falah Bondowoso \\ E-mail: Andi.susanto1947@gmail.com
}

\section{Abstrak}

Pemahaman tentang arah kiblat sangatlah penting bagi umat Islam, karena menghadap kiblat merupakan salah satu syarat sah dalam melaksanakan ibadah shalat. Meskipun kini teknologi untuk menentukan arah kiblat sudah canggih, namun perlu diketahui bagaimana cara menentukan arah kiblat yang sebenarnya. Penentuan arah kiblat dengan metode segitiga bola didasari oleh segitiga pada permukaan bola bumi yang dibentuk oleh tiga lingkaran besar bola bumi, yaitu dua lingkaran garis bujur bumi dan satu lingkaran kiblat. Perpotongan ketiga lingkaran besar tersebut membentuk tiga buah titik, yaitu titik A (Makkah), titik B (lokasi yang akan dihitung arah kiblatnya), dan titik C (Kutub Utara). Langkah-langkah dalam penentuan arah kiblat diantaranya: (1) Disiapkan data-data yang dibutuhkan dalam perhitungan arah kiblat suatu tempat, yaitu data lintang dan bujur Ka'bah (kota Makkah), serta data lintang dan bujur tempat lokasi/kota yang akan dihitung arah kiblatnya; (2) Penghitungan arah kiblat dengan menggunakan rumus $\cot \mathrm{B}=\frac{\cot \mathrm{s} \sin \mathrm{a}}{\sin \mathrm{C}}+\cos \mathrm{a} \cot \mathrm{C}$, dengan: $\mathrm{B}=$ Sudut arah kiblat suatu tempat, $\mathrm{C}=$ Selisih bujur Ka'bah dengan bujur tempat yang dicari arah kiblatnya, a $=90^{\circ}-\varphi$ tp (lintang tempat), dan $b=90^{\circ}-\varphi$ ka (lintang Ka'bah); (3) Penghitungan azimuth kiblat sejati dari arah utara sejati searah jarum jam, dimana azimuth kiblat sejati $=$ $360^{\circ}$ - sudut arah kiblat (B); (4) Penentuan arah kiblat sebenarnya dengan mengukur menggunakan penggaris busur sebesar azimuth kiblat sejati dari utara sejati.

Kata kunci : segitiga bola, lingkaran besar bola bumi, arah kiblat, sudut arah kiblat, azimuth kiblat 


\section{Pendahuluan}

Umat Islam diwajibkan untuk mendirikan shalat karena shalat merupakan tiang dari agama. Dalam melaksanakan shalat, umat islam diwajibkan untuk menghadap kiblat karena menghadap kiblat merupakan syarat wajib dalam melaksanakan shalat. Secara bahasa kiblat berasal dari bahasa Arab yaitu yang berarti arah. Kata kiblat juga telah Bahasa Indonesia yang baku yang berarti arah ke Ka'bah di Mekah. Sedangkan secara istilah, menurut Muhyidin Khazin yang dimaksud dengan kiblat adalah arah yang menuju Ka'bah di Mekah dimana dimana seorang muslim wajib menghadapkan mukanya ke sana ketika mendirikan shalat (Rahmi, 2008: 43).

Dasar hukum yang membicarakan tentang arah kiblat, diantaranya firman Allah SWT dalam surah al-Baqarah ayat 144 yang berbunyi:

"Sungguh Kami (sering) melihat mukamu menengadah ke langit, Maka sungguh Kami akan memalingkan kamu ke kiblat yang kamu sukai. Palingkanlah mukamu ke arah Masjidil Haram. dan dimana saja kamu berada, Palingkanlah mukamu ke arahnya. dan Sesungguhnya orang-orang (Yahudi dan Nasrani) yang diberi Al kitab (Taurat dan Injil) memang mengetahui, bahwa berpaling ke Masjidil Haram itu adalah benar dari Tuhannya; dan Allah sekali-kali tidak lengah dari apa yang mereka kerjakan."

Mengingat pentingnya arah kiblat dalam menjalankan ibadah shalat, maka hal utama yang harus dipersiapkan ketika akan membangun sebuah mushola atau masjid adalah arah kiblat. Begitu pula ketika akan melaksanakan shalat Ied di lapangan terbuka (tanah lapang). Mengerjakan shalat Ied di tanah lapang adalah sunah, kecuali karena ada hujan atau penghalang lainnya. Oleh karena itu, pengaturan shaf shalat di lapangan terbuka tidak bisa sembarangan, tetapi harus berdasarkan arah kiblat dengan tepat.

Kiblat bagi orang yang shalat dan dapat melihat Ka'bah adalah menghadap ke bangunan Ka'bah, sedangkan kiblat bagi orang yang shalat dan tidak dapat melihat Ka'bah adalah arah Ka'bah. Secara geografis, Indonesia berada di sebelah timur Makkah (Ka'bah). Meskipun demikian, arah kiblat bagi umat muslim yang ada di 
Indonesia tidak hanya sekedar mengarah ke barat. Hal tersebut telah dijelaskan oleh Komisi Fatwa Majelis Ulama Indonesia Pusat melalui Fatwa MUI No. 5 Tahun 2010 yang menyatakan bahwa kiblat umat Islam di Indonesia adalah menghadap ke barat laut dengan posisi bervariasi sesuai dengan letak kawasan masing- masing. Artinya, perlu ada perhitungan arah kiblat pada setiap kawasan. Sedangkan untuk bangunan masjid atau mushola yang tidak tepat arah kiblatnya, tidak perlu membongkar bangunannya, cukup dengan menata ulang shafnya (Majelis Ulama Indonesia, 2010).

Beberapa masjid di Indonesia arah kiblatnya belum tepat atau sekedar mengarah ke barat. Jika diperhatikan, meskipun kiblatnya belum tepat tetapi masih banyak jama'ah yang ketika menunaikan ibadah shalat shafnya menghadap lurus ke depan. Beberapa contoh masjid di Indonesia yang arah kiblatnya belum tepat diantaranya, Masjid AlMuhtadin di Cibinong dengan kesalahan sekitar $22^{\circ}$ (hasil Google Earth), Masjid Agung di Palu dengan kesalahan sekitar $7^{\circ}$ (hasil Google Earth), Masjid Al-Atiiq Kauman Salatiga dengan tingkat kemiringan kurang tepat (menurut Depag Salatiga), dan Masjid Agung Demak Jawa Tengah arah kiblatnya melenceng (hasil pengukuran Badan Hisab Rukyat, Kementrian Agama RI Jawa Tengah tanggal 13 Desember 2011).

Seiring dengan perkembangan ilmu pengetahuan dan teknologi yang modern, penentuan arah kiblat semakin mudah dilakukan, lebih tepat, dan lebih akurat. Misalnya, teknologi GPS (Global Positioning System) dan Theodolite Digital sebagai alat ukur sudut untuk menunjukkan arah kiblat yang akurat. Beberapa software penentuan arah kiblat seperti google earth, qibla locator, dan qibla direction juga dapat dimanfaatkan untuk mengecek arah kiblat bangunan masjid atau mushala yang dilihat dari atas permukaan Bumi. Selain itu, hanya dengan menggunakan aplikasi arah kiblat pada smartphone, dimanapun dapat ditentukan arah kiblatnya. Dengan demikian, kesalahan dalam menentukan arah kiblat dapat diminimalisasi dan arah kiblat dari masjid atau mushola yang sudah terlanjur dibangun dapat dibenarkan dengan mengubah arah shaf/baris tanpa merubah bangunan fisik masjid atau mushola.

Meskipun teknologi untuk menentukan arah kiblat kini sudah canggih, namun secara ilmiah perlu diketahui bagaimana cara menentukan arah kiblat yang 
sebenarnya. Sebagai mahasiswa fisika yang pernah mempelajari tentang segitiga bola, dasar tersebut dapat digunakan untuk mencari arah kiblat (arah Kota Makkah) dari suatu daerah atau kota tertentu di permukaan bumi.

\section{Pembahasan}

\section{Lingkaran Besar dan Lingkaran Kecil}

Hambali (2013: 12) menjelaskan bahwa bola bumi terbentuk oleh dua macam lingkaran, yaitu lingkaran besar (great circle) dan lingkaran kecil (small circle). Lingkaran besar merupakan lingkaran yang titik pusatnya sama dengan titik pusat bola bumi. Sedangkan lingkaran kecil merupakan lingkaran yang titik pusatnya bukan di titik pusat bola bumi, melainkan berada pada garis tengah bola bumi. Bola bumi mempunyai banyak lingkaran besar, diantaranya adalah lingkaran-lingkaran garis bujur dan lingkaran ekuator bumi. Sedangkan lingkaran kecil yang ada di bola bumi salah satunya adalah lingkaran garis lintang.

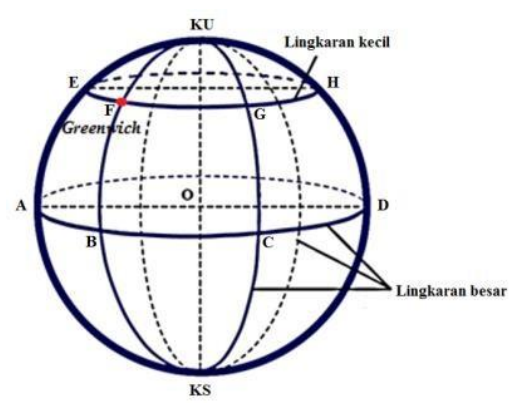

Gambar 2.1 Lingkaran Besar dan Lingkaran Kecil Bola Bumi

Pada bola bumi, untuk menentukan posisi suatu tempat digunakan sistem koordinat. Dalam sistem koordinat bumi, sumbu $\mathrm{X}$ yang ada dalam sistem koordinat kartesius digantikan dengan garis lintang, sedangkan sumbu Y digantikan dengan garis bujur. Garis lintang adalah bagian dari lingkaran kecil pada permukaan bola bumi yang berada di antara kutub utara dan kutub selatan bumi, dan berpotongan tegak lurus dengan garis bujur (Hambali, 2013: 13). Garis bujur adalah bagian dari lingkaran besar pada permukaan bola bumi yang menghubungkan kutub utara dan kutub selatan 
bumi (Anugraha, 2012: 27). Garis lintang yang membagi bumi menjadi belahan bumi utara dan belahan bumi selatan disebut ekuator bumi. Sedangkan garis bujur yang membelah bumi menjadi dua bagian yaitu bagian barat dan bagian timur disebut meridian bumi. Garis meridian yang melalui kota Greenwich di London dinamakan Meridian Utama (Prime Meridian).

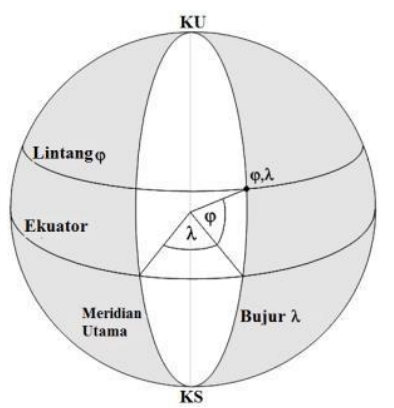

\section{Gambar 2.2 Sudut Garis Bujur $(\boldsymbol{\lambda})$ dan Sudut Garis Lintang $(\varphi)$}

Pada Gambar 2.2, sudut garis bujur ( $\lambda$ ) adalah busur/jarak yang dihitung dari meridian utama ke timur atau ke barat sampai suatu titik tertentu pada bola bumi. Meridian utama mempunyai harga bujur $0^{\circ}$, dengan kisaran harga bujur antara $0^{\circ}$ sampai $180^{\circ}$ ke Timur atau ke Barat. Sedangkan, sudut garis lintang ( $\varphi$ ) adalah busur/jarak yang diukur pada suatu meridian antara tempat tersebut ekuator. Lintang mempunyai harga $0^{\mathrm{O}}$ di ekuator sampai $90^{\circ}$ di kutub utara dan kutub selatan. Satuan sudut bujur dan sudut lintang tempat pada bola bumi dinyatakan dengan derajat, menit busur, dan detik busur yang disimbolkan dengan ( ${ }^{\circ}$, ', "). Misalnya $39^{\circ} 49^{\prime} 34$ " BT dibaca 39 derajat 49 menit 34 detik, dimana $1^{\circ}=60$ ' $=3600$ ”. Perlu diingat bahwa meskipun menggunakan kata menit dan detik, namun nilai tersebut memiliki satuan sudut dan bukan satuan waktu (Anugraha, 2012: 27).

\subsection{Segitiga Bola}

Menurut Basuki (1988: 25) segitiga bola adalah bagian dari permukaan bola yang dibatasi oleh tiga busur lingkaran besar. Pada Gambar 2.3, segitiga bola adalah bagian permukaan bola yang dibatasi oleh tiga busur lingkaran besar dengan titik-titik sudut A, B, dan C. Sisi-sisi di hadapan sudut A, B, dan C disebut dengan sisi-sisi a, 
b, dan c. Radius bola dianggap sama dengan satu satuan panjang. Sudut-sudut BOC, AOC, dan AOB masing-masing benarnya a, b, dan c karena berhadapan dengan sisisisi a, b, dan c.

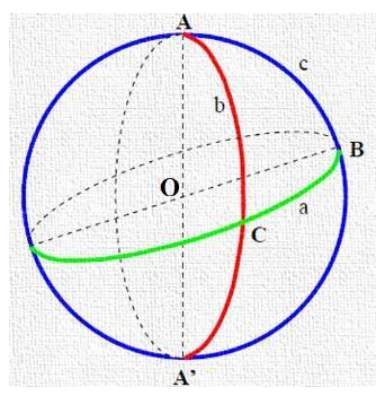

Gambar 2.3 Segitiga Bola

Sifat-sifat sudut segitiga bola:

1. Jumlah tiga buah sudut sebuah segitiga bola lebih besar dari $180^{\circ}$.

Bukti:

Luas segitiga bola $=$

\section{$\frac{\mathrm{A}+\mathrm{B}+\mathrm{C}-180^{\circ}}{270^{\circ}} \times$ Luas Permukaan Bola}

luas permukaan bola ini adalah positif

$$
\mathrm{A}+\mathrm{B}+\mathrm{C}-180^{\circ}>0
$$

sehingga

$$
\mathrm{A}+\mathrm{B}+\mathrm{C}>180^{\circ}
$$

2. Dalam sebuah segitiga bola, jumlah dua sudut dikurangi sudut yang lain kurang dari $180^{\circ}$.

Bukti:

$$
\begin{aligned}
& <\mathrm{A}^{\prime} \mathrm{CB}+<\mathrm{A}^{\prime} \mathrm{BC}+<\mathrm{A}^{\prime} 180^{\circ} \\
& \leftrightarrow\left(180^{\circ}-C\right)\left(180^{\circ}-B\right)+\mathrm{A}>180^{\circ} \\
& \leftrightarrow C+B-\mathrm{A}>180^{\circ}
\end{aligned}
$$


3. Jumlah ketiga sudut sebuah segitiga bola lebih kecil dari $540^{\circ}$.

Bukti:

$\mathrm{A}+\mathrm{B}-\mathrm{C}<180^{0}$

$\mathrm{A}+\mathrm{C} \quad 180^{\circ}$

$-\mathrm{B}<$

$+\mathrm{C} \quad 180^{\circ}$

B $\quad-A<$

$\mathrm{A}+\mathrm{B} \quad 540^{\circ}$

$+\mathrm{C}<$

Sifat sisi segitiga bola:

Jumlah sisi-sisi segitiga bola harus lebih dari $0^{\circ}$ dan kurang dari $360^{\circ}$.

Bukti:

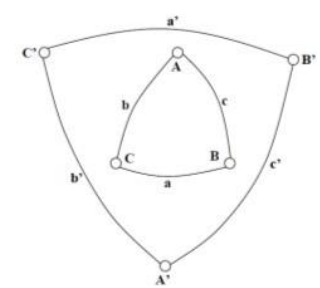

Gambar 2.4 Segitiga Kutub

$\mathrm{A}^{\prime} \mathrm{B}^{\prime} \mathrm{C}^{\prime}$ adalah segitiga kutub dari segitiga bola $\mathrm{ABC}$.

$\mathrm{A}^{\prime}+\mathrm{B}^{\prime}+\mathrm{C}^{\prime}>180^{\circ}$

$\mathrm{A}^{\prime}=180^{\circ}-\mathrm{a}$

$\mathrm{B}^{\prime}=180^{\circ}-\mathrm{b}$

$\mathrm{C}^{\prime}=180^{\circ}-\mathrm{c}$

Sehingga,

$\left(180^{\circ}-\mathrm{a}\right)+\left(180^{\circ}-\mathrm{b}\right)+\left(180^{\circ}-\mathrm{c}\right)>180^{\circ}$

$-(\mathrm{a}+\mathrm{h}+\mathrm{c})+540>180^{\circ}$

$\mathrm{a}+\mathrm{b} \rightarrow \mathrm{c}<360^{\circ}$ 
Rumus Cosinus untuk sisi segitiga bola:

$\operatorname{Cos} a=\operatorname{Cos} b \operatorname{Cos} c+\operatorname{Sin} b \operatorname{Sin} c \operatorname{Cos} A \ldots \ldots)$

$\operatorname{Cos} b=\operatorname{Cos} a \operatorname{Cos} c+\operatorname{Sin} a \operatorname{Sin} c \operatorname{Cos} B \ldots \ldots()$

$\operatorname{Cos} c=\operatorname{Cos} a \operatorname{Cos} b+\operatorname{Sin} a \operatorname{Sin} b \operatorname{Cos} C \ldots \ldots()$

Rumus Sinus untuk segitiga bola:

$\frac{\operatorname{Sin} \mathrm{a}}{\operatorname{Sin} A}+\frac{\operatorname{Sin} \mathrm{b}}{\operatorname{Sin} B}+\frac{\operatorname{Sin} \mathrm{c}}{\operatorname{Sin} C} \ldots \ldots \ldots \ldots$

\subsection{Arah Kiblat}

Arah kiblat adalah arah terdekat menuju Ka'bah melalui lingkaran besar (great circle) bola bumi. Lingkaran besar bola bumi yang dilalui arah kiblat disebut dengan lingkaran kiblat. Lingkaran kiblat (Hambali, 2013: 14) merupakan lingkaran besar bola bumi yang memiliki sumbu atau poros kiblat. Sumbu atau poros adalah garis tengah bola bumi yang menghubungkan Ka'bah dengan kebalikan dari Ka'bah melalui titik pusat bumi.

Duffett-Smith, Peter (1981: 28-29) dan A. E. Roy and D. Clarke (1988: 46) menyatakan bahwa arah menghadap kiblat disebut dengan azimuth (arah relatif terhadap titik utara).

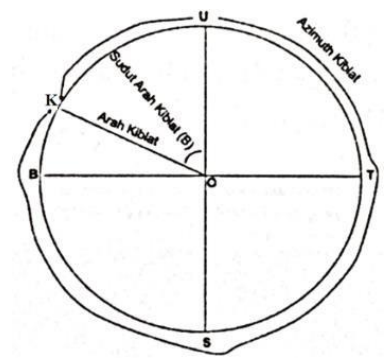

Gambar 2.8 Arah Kiblat (OK), Sudut Arah Kiblat (UK), dan Azimut Kiblat (UTSBK) 


\subsection{Penentuan Arah Kiblat dengan Metode}

\section{Segitiga Bola}

Segitiga bola dalam penentuan arah kiblat adalah segitiga pada permukaan bola bumi yang dibentuk oleh tiga lingkaran besar bola bumi, yaitu dua lingkaran garis bujur dan satu lingkaran kiblat. Oleh karenanya dalam penentuan arah kiblat diperlukan tiga buah titik, yaitu:

1. titik A, terletak di Ka'bah (Makkah);

2. titik B, terletak di lokasi yang akan dihitung arah kiblatnya; dan

3. titik C, terletak di kutub Utara.

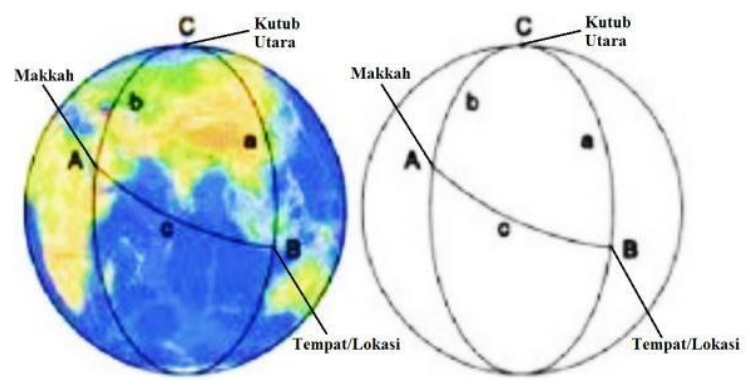

Gambar 2.9 Segitiga Bola Arah Kiblat

Pada diatas, segitiga bola arah kiblat menghubungkan titik A (Makkah), titik B (lokasi), dan titik C (Kutub Utara). Titik A memiliki koordinat bujur $\lambda$ A dan lintang $\varphi$ A. Titik B memiliki koordinat bujur $\lambda B$ dan lintang $\varphi B$. Sedangkan titik C memiliki lintang $90^{\circ}$. Busur a adalah busur yang menghubungkan titik B dan C. Busur $\mathrm{b}$ adalah busur yang menghubungkan titik A dan $\mathrm{C}$. Busur $\mathrm{c}$ adalah busur yang menghubungkan titik A dan B. Sudut $C$ adalah selisih antara bujur $\lambda A$ dan bujur $\lambda B$. Jadi, arah kiblat dari titik B dapat diketahui dengan menentukan besar sudut B. Sudut yang menghubungkan ekuator, pusat bumi, dan kutub utara adalah $90^{\circ}$. Karena lintang titik $\mathrm{A}$ adalah $\varphi \mathrm{A}$, maka busur $\mathrm{b}$ sama dengan $90^{\mathrm{O}}-\varphi \mathrm{A}$. Dan karena lintang B adalah $\varphi \mathrm{B}$, maka busur a sama dengan $90^{\circ}-\varphi \mathrm{B}$. 
Rumus yang digunakan untuk mencari sudut arah kiblat (B) didapat dari persamaan sebelumnya:

$\operatorname{Cot} B=$

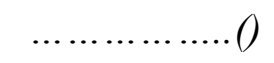

$$
\frac{\cot b+\operatorname{Sin} a}{\sin C}+\operatorname{Cos} a \operatorname{Cot} C
$$

dimana:

$\mathrm{B}=$ Sudut arah kiblat suatu tempat

$\mathrm{C}=$ Selisih antara bujur Ka'bah dengan bujur tempat yang akan dicari arah kiblatnya

$\mathrm{a}=90^{\circ}-\varphi \mathrm{tp}$ (lintang tempat)

$\mathrm{b}=90^{\circ}-\varphi \mathrm{ka}$ (lintang Ka'bah)

Sudut arah kiblat yang telah dihitung menggunakan persamaan (27), selanjutnya digunakan untuk mencari azimuth kiblat sejati. Azimuth kiblat sejati merupakan arah relatif terhadap utara sejati. Utara sejati (true north) atau utara geografis adalah utara yang berimpit dengan garis meridian dan menunjuk ke kutub utara geografis yang dilalui sumbu bumi. Penentuan utara sejati dapat dilakukan dengan beberapa cara, diantaranya adalah menggunakan kompas dan menggunakan bayangbayang matahari.

\section{Menggunakan Kompas}

Kelemahan pengukuran utara sejati dengan kompas menurut Izzuddin (2012: 211-212) adalah:

a. Kompas tidak menunjukan arah utara selatan sejati (geografis), tetapi arahnya menunjukan kutub utara dan selatan magnet bumi.

b. Antara arah penunjuk kompas dengan arah utara selatan sejati (geografis) terdapat sudut deklinasi kompas yang nilainya berbeda-beda di setiap tempat.

c. Kompas dipengaruhi besi-besi di sekitarnya

d. Kompas mudah hilang kemagnetannya bila terjatuh atau terkena panas.

Cara pengukuran utara sejati dengan menggunakan kompas adalah (Slamet Hambali, 2013: 24):

1) Siapkan kompas yang masih dalam keadaan baik.

2) Siapkan deklinasi magnetik tempat yang ditentukan arah kiblatnya 
3) Koreksikan deklinasi magnetik, dengan cara: Azimuth magnetik = azimuth kiblat sejati - deklinasi magnetik.

4) Buat garis pada skala kompas yang menunjukan azimuth magnetik (azimuth kiblat sejati yang telah dikoreksi magnetik), kemudian letakan kompas di telapak tangan hingga garis (azimuth magnetik) searah dengan kemana kita menghadap.

5) Putar badan bersama kompas di tangan hingga ujung jarum kompas yang berwarna merah (utara) berhimpit dengan utara pada skala kompas, yang artinya telah menghadap ke arah kiblat.

\section{Menggunakan Bayang-bayang Matahari}

Berikut langkah-langkah untuk melakukannya (Ahmad Izzan, 2013):

a. Pilih tempat yang rata, datar, terbuka, dan terkena sinar matahari langsung di tengah hari.

b. Buatlah sebuah lingkaran.

c. Tancapkan atau letakan sebuah tongkat tegak lurus tepat di tengah lingkaran.

d. Kira-kira 1 jam sebelum dhuhur, amati bayangan ujung tongkat hingga tepat masuk dan menyentuh garis lingkaran, kemudan beri tanda dengan huruf B (Barat).

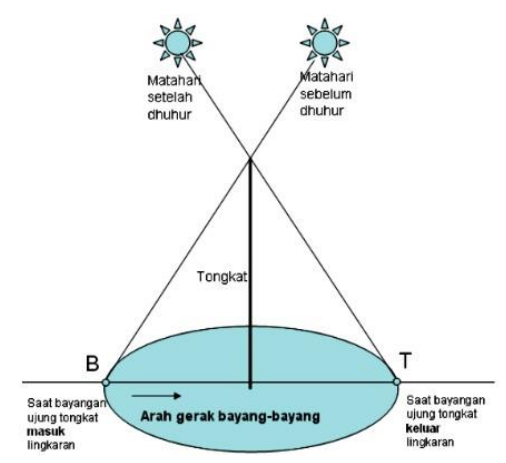

Gambar 2.14 Penentuan Arah Utara dengan bayang-bayang matahari

e. Setelah dhuhur, amati kembali bayangan tongkat hingga bayangannya menyentuh lingkaran dan beri tanda dengan huruf T (Timur).

f. Hubungkan titik B (Barat) dan $\mathrm{T}$ (Timur) tersebut dengan garis lurus. Garis ini adalah garis yang menunjukan Barat dan Timur.

g. Buatlah garis Utara-Selatan yang tegak lurus dengan garis Barat-Timur.

h. Selanjutnya ukurlah sudut arah kiblat (B) atau azimuth kiblat sejati dengan pengukur sudut, misalnya menggunakan penggaris busur. 


\subsection{Contoh Penentuan Arah Kiblat}

Contoh penentuan arah kiblat dilakukan pada Masjid dan Musholla di Kecamatan Cermee Kabupaten Bondowoso, Jawa Timur Indonesia. Langkah-langkah menentukan arah kiblat Masjid dan Musholla, yaitu:

a. Menyiapkan data yang diperlukan dalam perhitungan arah kiblat, yaitu:

1. Data lintang dan Bujur Mekkah (Ka'bah) yaitu:

$\varphi$ Mekkah (Ka'bah) $=21^{0} 25^{\prime} 15^{\prime \prime} \mathrm{LU}$,

\. Mekkah $($ Ka'bah $)=39^{0} 49^{\prime} 40^{\prime \prime}$ BT

2. Data lintang dan bujur Masjid dan Musholla di Kecamatan Cermee Kabupaten Bondowoso, yaitu:

$\varphi$ Bondowoso : $-7^{0} 55^{\prime} \mathrm{LS}$

ג Bondowoso : $113^{0} 50$ ' BT

b. Menghitung sudut arah kiblat (B) menggunakan persamaan (27). Terlebih dahulu mencari nilai a, b, dan $\mathrm{C}$, sebagai berikut:

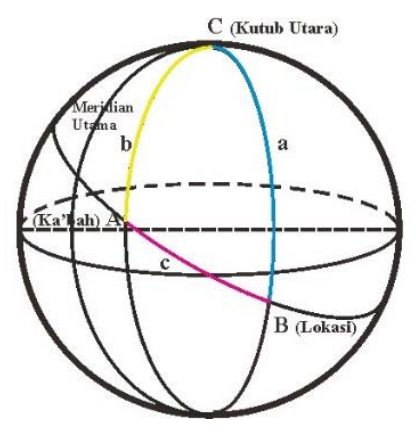

formula:

$$
\begin{array}{ll}
\mathrm{a}=90^{\circ}-\varphi \text { Bondowoso } & =90^{\circ}-\left(-7^{0} 55^{\prime}\right)=97^{0} 55^{\prime} \\
\mathrm{b}=90^{\circ}-\varphi \text { Ka'bah }(\text { Mekkah }) & =90^{\circ}-\left(21^{0} 25^{\prime} 15^{\prime \prime}\right)=68^{0} 34^{\prime} 45^{\prime \prime} \\
\mathrm{C}=\lambda \text { B Bondowoso }-\lambda \text { Ka'bah (Mekkah) } & =113^{0} 50^{0}-39^{0} 49^{\prime} 40^{\prime \prime}=74^{0} 00^{\prime} 20^{\prime \prime}
\end{array}
$$

Selanjutnya nilai a, b dan $\mathrm{C}$ tersebut dimasukkan ke dalam persamaan: 
Cot $B=$ , maka

$$
\begin{aligned}
& \frac{\operatorname{Cot} 68^{\circ} 34^{\circ} 45^{x}+\operatorname{Sin} 97^{\circ} 55^{x}}{\operatorname{Sin} 74^{\circ} 0^{\prime} 20^{x}}+\operatorname{Cos} 97^{\circ} 55^{\prime} \operatorname{Cot} 74^{\circ} 0^{\prime} 20^{\prime \prime} \\
& B=66^{\circ} 4^{\prime} 22,58^{\prime \prime} \mathrm{UB}
\end{aligned}
$$

\section{Azimuth Kiblat sejati:}

$360^{0}-66^{0} 4^{\prime} 22,58^{\prime \prime}=293^{0} 55^{\prime} 47^{\prime \prime}$ UTSB

c. Menentukan arah utara sejati.

1) Menggunakan kompas Terlebih dahulu dilakukan koreksi deklinasi magnetik. Deklinasi magnetik Surakarta yaitu $+1^{\mathrm{O}} 0^{\prime} \mathrm{E}$, sehingga azimuth magnetiknya = $293^{0} 55^{\prime} 47^{\prime \prime}-1^{0} 0^{\prime}=292^{\circ} 32^{\prime} 07,39^{\prime}$. Selanjutnya, memutar badan bersama kompas di tangan dengan arah badan searah dengan azimuth magnetik, hingga ujung jarum kompas yang berwarna merah (utara) berhimpit dengan utara skala kompas. Jika sudah berhimpit, artinya kita telah menghadap ke arah kiblat.

2) Menggunakan bayang-bayang matahari Terlebih dahulu mencari arah utara sejati dengan menggunakan bayangan tongkat. Selanjutnya, melakukan pengukuran sudut sebesar azimuth kiblat sejati yaitu sebesar $293^{0} 55^{\prime} 47^{\prime \prime}$ dari utara searah jarum jam (UTSB) Atau sebesar sudut arah kiblat (B) yaitu $66^{0} 4$ ' 22,58" dari arah utara ke barat (UB). Setelah arahnya diperoleh, ditarik sebuah garis lurus ke dalam masjid dengan menggunakan tali rafia hingga saling tegak lurus (membentuk sudut $90^{\circ}$ ) dengan shaf sholat untuk menunjukan arah kiblat Masjid dan Musholla. Hasilnya menunjukkan bahwa arah kiblat Masjid dan Musholla di kecamatan Cermee sesuai perhitungan sudut arah kiblat dengan metode segitiga bola. 


\section{Penutup}

Berdasarkan analisis yang telah dilakukan, dapat disimpulkan bahwa penentuan arah kiblat dengan metode segitiga bola didasari oleh segitiga pada permukaan bola bumi yang dibentuk oleh tiga lingkaran besar bola bumi, yaitu dua lingkaran garis bujur bumi dan satu lingkaran kiblat. Perpotongan ketiga lingkaran besar tersebut membentuk tiga buah titik, yaitu titik A (Makkah), titik B (lokasi yang akan dihitung arah kiblatnya), dan titik C (Kutub Utara). Langkah-langkah dalam penentuan arah kiblat adalah sebagai berikut:

1. Dipersiapkan data-data dalam perhitungan arah kiblat suatu tempat, yaitu:

a. data lintang dan bujur Ka'bah

b. data lintang dan bujur tempat lokasi/kota yang akan dihitung arah kiblatnya.

2. Penghitungan arah kiblat (B) dengan menggunakan rumus:

$\operatorname{Cot} B=$

$$
\frac{\cot b+\sin a}{\sin C}+\operatorname{Cos} a \operatorname{Cot} C
$$

Dengan:

$\mathrm{B}=$ Sudut arah kiblat suatu tempat

$\mathrm{C}=$ Selisih bujur Ka'bah dengan bujur tempat yang dicari arah kiblatnya

$\mathrm{a}=90^{\mathrm{O}}-\varphi \operatorname{tp}($ lintang tempat)

$\mathrm{b}=90^{\circ}-\varphi \mathrm{ka}($ lintang Ka'bah)

3. Penghitungan azimuth kiblat sejati dari utara sejati.

Azimuth kiblat sejati $=360^{\circ}-$ sudut arah kiblat $(\mathrm{B})$

4. Penentuan arah kiblat sejati dengan mengukur menggunakan penggaris busur sebesar azimuth kiblat sejati dari utara sejati searah jarum jam.

\section{Saran}

1. Gunakan data lintang dan bujur tempat sesuai tempat yang akan dicari arah kiblatnya.

2. Gunakan data deklinasi magnetik yang terbaru sesuai waktu penentuan arah kiblatnya, karena besar deklinasi magnetik tidak sama setiap waktunya. 
3. Kebanyakan kompas tidak bisa membaca azimuth magnetik kiblat dengan sangat teliti karena skala terkecil kompas pada umumnya antara $2^{0}-5^{0}$, sehingga azimuth magnetik kiblat harus dibulatkan terlebih dahulu. Oleh karena itu, sebaiknya gunakan kompas dengan ketelitian $1^{\mathrm{O}}$ atau kurang.

4. Penggunaan bayang-bayang sinar matahari pada penentuan arah kiblat tidak ada hubungannya dengan penentuan waktu shalat. Meskipun bayangan yang terbentuk akibat sinar matahari dapat menunjukan waktu shalat, tetapi bukan berarti arah bayangan tersebut menunjukkan arah kiblat suatu tempat. Pada penentuan arah kiblat, arah bayangan yang terbentuk akibat sinar matahari digunakan untuk menentukan arah utara sejati sebagai titik acuan pengukuran sudut arah kiblat. 


\section{Daftar Pustaka}

A. E. Roy and D. Clarke. 1988. Astronomy: Principles and Practices. Bristol: Adam Hilger Ltd.

Ahmad Izzan. 2013. Studi Ilmu Falak. Tangerang: Pustaka Aufa Media

Basuki K, S. 1988. Segitiga Bola. Yogyakarta: Kanisius

Majelis Ulama Indonesia. 2010. Himpunan Fatwa Majelis Ulama Indonesia,

Fatwa Terbaru 2010, Fatwa No.05 Tahun 2010 Tentang Kiblat. Jakarta:

Majelis Ulama Indonesia

Moedji Raharto. 2011. Tata Koordinat Astronomi: Segitiga Bola. Bandung: Institut Teknologi Bandung

Rinto Anugraha. 2012. Mekanika Benda Langit. Yogyakarta: Jurusan Fisika Fakultas MIPA Universitas Gajah Mada

Slamet Hambali. 2013. Ilmu Falak: Arah Kiblat Setiap Saat. Yogyakarta: Pustaka Ilmu Yogyakarta 